Review

\title{
Traditional uses, phytochemistry and pharmacological profile of Bambusa arudinacea Retz
}

\author{
Vishal Soni ${ }^{1, *}$, Arvind Kumar Jha $^{2}$, Jaya Dwivedi ${ }^{3}$, Priyanka Soni ${ }^{1}$ \\ ${ }^{I}$ Department of Herbal Drug Research, B.R. Nahata College of Pharmacy, Research Centre, Mhow Neemuch Road, Mandsaur 458 \\ 001, India; ${ }^{2}$ Faculty of Pharmaceutical Sciences, Shri Sankarachary group of Institution, Shri Sankarachary Technical Campus, \\ Junwani Bhilai Chattisghur, 490020; ${ }^{3}$ Department of chemistry, Banasthali Vidyapith Banasthali University, Rajasthan, 304022
}

\begin{abstract}
Bambusa arundinacea family Graminae, is one of the precious plant resources of the earth. It has played a significant role in human civilization since ancient times. It is tall sized tree growing throughout India, moist parts of India. It also occurs in Sri Lanka, Malaya, Peru and Myanmar. The different parts of this plant contain silica, cholin, betain, cynogenetic glycosides, albuminoids, oxalic acid, reducing sugar, resins, waxes, benzoic acid, arginine, cysteine, histidine, niacin, riboflavin, thiamine, protein, gluteline, contains lysine, methionine, betain, cholin, proteolytic enzyme, nuclease, urease. Various parts of this plant such as leaf, root, shoot and seed possess anti-inflammatory, antiulcer, anti-diabetic, anti-oxidant, anthelmintic, antifertility, antibacterial, insectisidal, antiarthritic, vessele protection etc. This review mainly focuses on the traditional, phytochemical and pharmacological information of Bambusa arundinacea.
\end{abstract}

Keywords Bambusa arundinacea, phytopharmacological properties, phytochemicals, traditional uses

\section{INTRODUCTION}

In recent years, focus on plant research has increased all over the world and evidence show immense potential of medicinal plants used in various traditional systems. Herbal drugs have got tremendous momentum in global health care system. Many plants have been found to have therapeutic potential and are being used since time immemorial. The beneficial therapeutic effect of these medicinal herbs is seen in their continued use and proven scientifically (Jarald et al, 2007). Bamboo is one of the precious plant resources of the earth. It has play a significant role in human civilization since ancient times, and is still contributing to the subsistence of over two billion people living in tropical and subtropical belts in Asia, Latin America and Africa (Kiruba et al, 2007) B. arundinacea (Poaceae) is commonly known as bans. A bamboo culm consists of internodes (which are hollow for most bamboo) and a node, which is solid and provides structural integrity for the plant. At the node are one or more buds (depending on the species) which produce side branches. Traditional use of bamboo is differing from region to region and people to people. Since time immemorial, bamboo is used in fuel, food, housing and shelter by indigenous community (Kumar, 2012). The leaves of $B$. arundinacea are emmenogogue and are used as a folk medicine for the treatment of cough, fever and leprosy. $B$. arundinacea (Poaceae) is commonly known as bans. A bamboo culm consists of internodes (which are hollow for most bamboo) and a node, which is solid and provides structural integrity for the plant (Rastogi and Mehrotra, 1993; Patrick, 2011)). The plants contain flavanoids, phenolics, amino acids, proteins

"Correspondence: Vishal Soni

E-mail: vishalpanacea@rediffmail.com

Received May 3, 2013; Accepted August 5, 2013; Published August 31,2013

doi: http://dx.doi.org/10.5667/tang.2013.0011

CC2013 by Association of Humanitas Medicine glucosides. The young shoot contains poisonous cynogenic glucosides $(0.3 \%)$ and taxiphyllain. Bamboo-manna (Vanslochan) contains silica or silicon as hydrates of silicic acid potash, alumina, iron peroxide, and calcium carbonate (Gupta, 2008). It was reported that the extract of $B$. arundinacea showed anti-inflammatory, antiulcer, antifertility, antimicrobial and hypoglycemic activities. The hypoglycemic properties of extracts of bambusa leaves have also been established. A previous research on this plant has resulted in the isolation of flavones glycosides (Nazreen et al, 2011). The root (burnt root) is applied to ringworm, bleeding gums, painful joints. Seeds are acrid, laxative, said to be beneficial in strangury and urinary discharge. Bark is used for skin eruptions. Leaf is emmenagogue, antileprotic, febrifuge used in haemoptysis (Rathod et al, 2012). Bamboos, a group of arborescent grasses, have closely been associated with mankind since ancient time (Watt, 1972). They are used for a variety of purposes such as mat making, traditional instruments, furniture, musical instruments, flooring and construction materials, paper making, fencing, fodder, fuel wood, cooking utensils, floats for timber and rafts, sericulture industry, and waste water management (Nazreen et al, 2011; Rathod et al, 2012).However there is lack of information about the use of bamboo plant. Hence, an attempt has been made to explore the indigenous knowledge about the use of this plant.

\section{Regional and other names}

Gujarati (Toncor, Wans, Vanskapur, Vas-nu-mitha); English (Bamboo, Bamboo manna, Giant Thorny Bamboo); Hindi (Bans-lochana, Banskapur, Vanoo , Banz); Bengoli (BansKapur,Baans, Baansh, Baroowa Bans); Sanskrit (Vanshalochana, Venulavanam); Arab (Tabashir); Marthi (Bansa, Baambii, Bansamitha); Tamil (Munga-luppa, Mullumangila, Mulmunkil, Mungil); Telugu (Veduruppu, Mulkas Veduru, Mullu Veduru); Maliyalam (Moleuppa); Kannad (Bidaruppu, Tavakshira); Burma (Vd-chha, Vathega- 


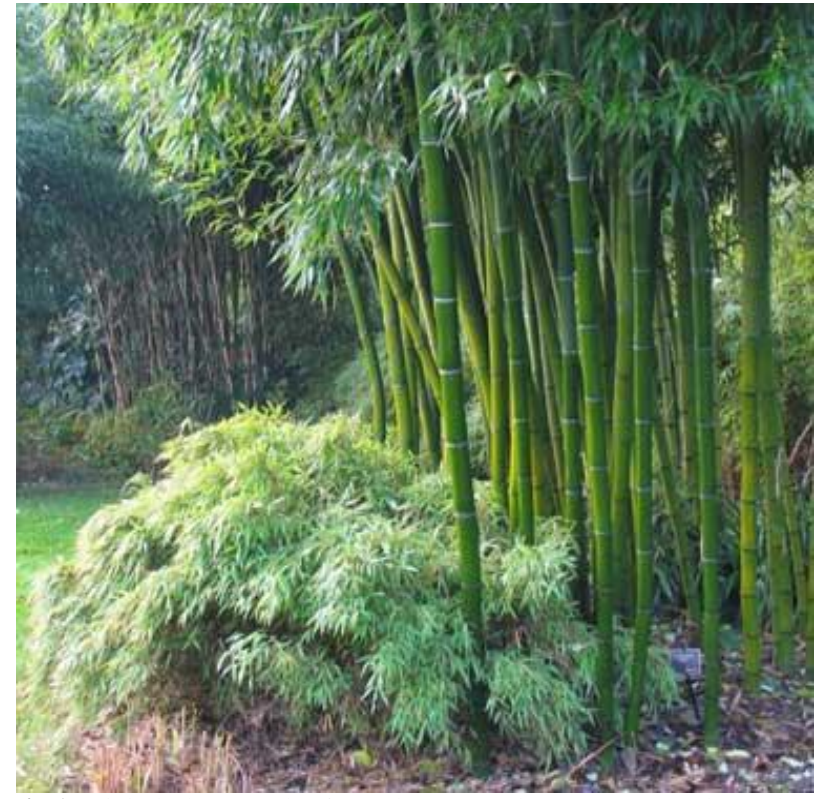

Fig.1. Digital photograph of Bambusa arundinacea (Retz.) plant taken from Jawer, Jhalawar district, Rajasthan, India.

kiyo, Vasan, Vathe gasu); Unani (Tabashir, Tawashir) (Rastogi and Mehrotra, 1993).

\section{Botanical description}

Thorny tree, stems many, tufted on a stout root-stock, grows upto 30 meter high; culms $15-18 \mathrm{~cm}$ across; nodes prominent, the lower emiting horizontal almost naked shoots armed at the nodes with 2-3 stout recurved spines; internodes upto $45 \mathrm{~cm}$. long (Santosh 2010; Anonymous,1996). Leaves 17.5 - 20.5 X 2-2.5 cm, linear or linear - lanceolate, tip stiff, glabrous or puberulous beneath, margins scabrous, base cilliate, mid-rib narrow, leaf-sheath ending on a thick callus and shortly bristly auricle. Inflorescence, enormous panicles often occupying the whole stem. Caryopsis (grain) oblong, 5-8 mm long, grooved on one side. Flowering and Fruiting: Once in life time, often during September - May (Anonymous, 1998; Jia, 2011; Chopra et al, 1958).

\section{Traditional medicinal uses}

The extract of the plant $B$. arundinacea Retz. had been used in folk medicines to treat various inflammatory conditions. In Ayurveda, the leaves, the stem and roots are used as astringent, laxative and as diuretic. An ointment from the root is said to be a folk remedy for cirrhosis and hard tumor. Shoot of $B$. arundinacea Retz. is used for dislodegement of worms from ulcer. Leaf bud (decoction) of $B$. arundinacea Retz. is used to encourage the free discharge of menses. Leaves are useful in leprosy, hematenesis, fever and haemoptysis. Leaves are also used in cough paralytic complications and in snake bites. An ointment from the $B$. arundinacea Retz. root is said to be a folk remedy for cirrhosis and tumors, especially tumor of abdomen, liver, spleen and stomach. Tabasheer, a siliceous secretion of $B$. arundinacea Retz. (up to $97 \% \mathrm{SiO}_{2}$ ), considered aphrodisiac, cooling, and tonic is used in asthma, cough. Leaves given to horse suffering from coughs and colds (Nandkarni, 2000). Tribal women around Salem in Tamilnadu chew leaves of $B$. arundinacea Retz. in the morning and evening for 1-3 days to induce abortion of an early conception (Bhaduri, 1968). The extracts of $B$. arundinacea have been used in Indian folk medicine to treat various inflammatory conditions. The plant has antiulcer activity also. It is thought that these two properties in the same extract are very useful in the treatment of inflammatory conditions. It is well known fact that the most of the available anti-inflammatory drugs are ulcerogenic (Muniappan, 2003). Leaves decoction is used to stimulate menstruation and as an antispasmodic to help relieve menstrual pain, in dysmenorrhoea and amenorrhea. A decoction of bamboo joints is said to increase the flow of lochia after delivery (Kirtikar, 1975). Bambusa leaf juice is given for strengthening the cartilage in osteoarthritis and osteoporosis. It plays a part in the integrity of the bones, arterial walls, skin, teeth, gums, hair and nails and has been used to alleviate eczema and psoriasis. It is used in diarrhoea, dyspepsia, flatulence and worm problems. Silicates of Bambusa are very useful in creation of the body's structural matrix for forming and repairing connective tissue (Vanithakumari, 1989). An ointment from the root is said to be a folk remedy for cirrhosis and hard tumors, especially tumors of the abdomen, liver, spleen and stomach. Tabasheer, a siliceous secretion (up to $97 \%$ $\mathrm{SiO}_{2}$ ), considered aphrodisiac, cooling, and tonic, is used in asthma, cough and debilitating diseases (C.S.I.R., 1948 - 1976) (Atal, 1982). Seeds of B. arundinacea Willd, by the Kani tribes of Kanyakumari district, southern Western Ghats. Method of seed collection, storage and mode of consumption by indigenous people has been described. The indigenous community not only uses the seeds as a food, but also as commercial commodity to improve the economy. The Kani tribes believe that the seeds of $B$. arundinacea enhance the fertility, so that there is great demand of seeds of this species in pharmaceutical industry to manufacture drugs to improve fertility (Kiruba et al, 2007).

\section{Phytochemical constituents}

Bamboo leaves have been used in traditional Chinese medicine for treating fever and detoxification for over 1000 years. Recently, some biologically active components in bamboo leaves and their potential health benefits have been widely studied. An ethanol/water extract of bamboo leaf mainly contains flavone glycosides, phenolic acids, coumarin lactones, anthraquinones and amino acids Many papers have indicated that a flavonoid-rich bamboo leaf extract has multiple biological effects, such as anti-free radical, anti-oxidation, antiaging, anti-fatigue, anti-bacteria, anti-virus, and prevention of cardiovascular diseases, and can be used as a pharmaceutical intermediate, dietary supplement, cosmetic ingredient, and food additive chemical investigation of this plant, triterpenes and

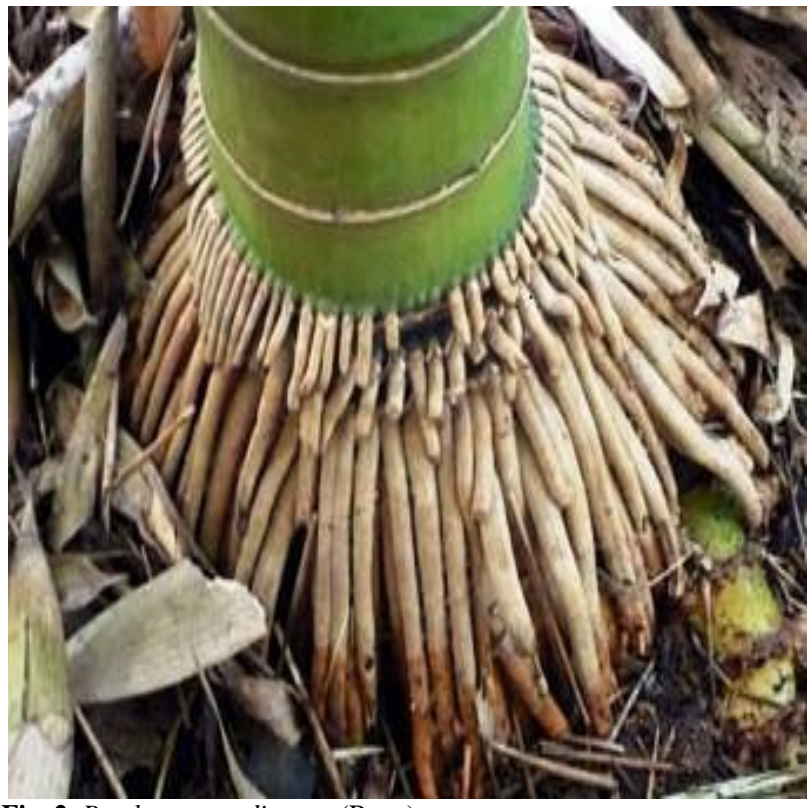

Fig. 2. Bambusa arundinacea (Retz.) root.

2013 / Volume 3 / Issue 3 / e20 


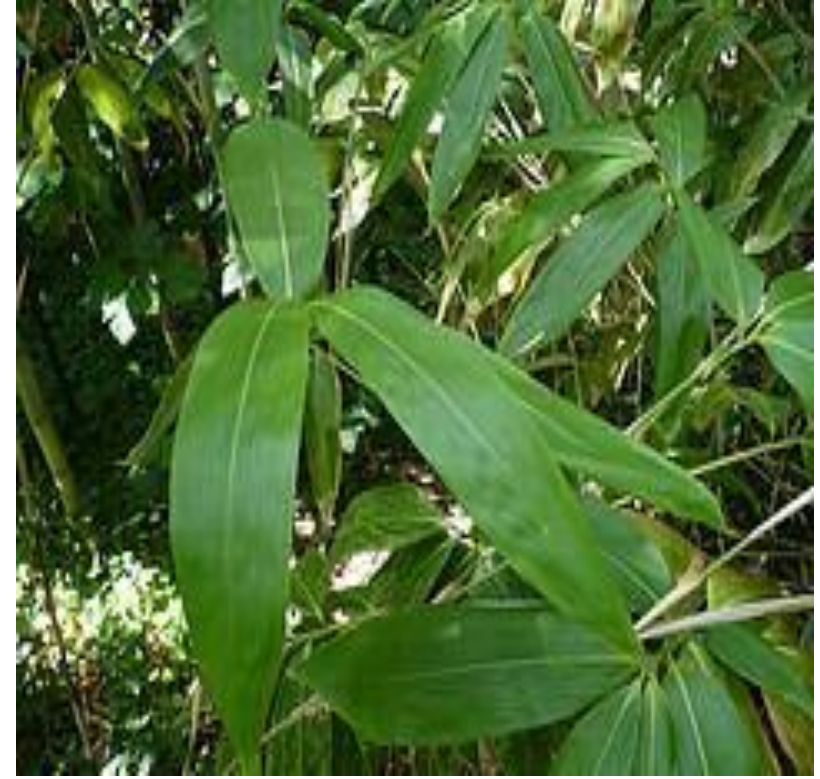

Fig. 3. Bambusa arundinacea (Retz.) leaves.

steroidal glycosides were the major phytoconstituents (Kiruba et al, 2007). In the course of phytochemical investigation of

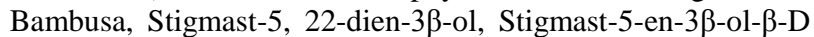
glucopyranoside were isolated in good quantities. The synergistic hypoglycemic effect of these two compounds has been well established. Along with the two new compounds i.e. 17, 20, 20-tri demethyl-20 $\alpha$-isopranyl oleanane and a new acid, eicosanyl dicarboxylic acid, another two known compounds $\alpha$ amyrin acetate and urs-12-en-3 $\beta$-ol- $\beta$-D-glucopyranosid have been isolated for the first time from this plant. The silicious substance found near the joint inside is white camphor like crystalline in appearance, slightly sticky to the tongue and sweet in taste (Watt, 1972). Shoot has active constituents are Oxalic acid, reducing sugar, resins, waxes, $\mathrm{HCN}$, benzoic aciddiferuloyl arabinoxylanhexasaccharide, diferuloyl oligosaccharide (Tadash, 1991), (5, 5'-di--(diferul-9, 9'-dioyl)[ $\alpha$-Larabinofuranosyl- $(1 \rightarrow 3)$ - O- $\beta$-D-xylopyranosyl-9 $(1 \rightarrow 4)-$ D xylopyranose] (taxiphyllin). Seed contain arginine, cysteine, histidine, isoleucine, leucine, lysine, methionine, phenylamine, threonine, valine, tyrosine, niacin, riboflavin, thiamine (TaiHung et al, 2009; Yeon Hee, 2010). Leaves mainly contain protein, gluteline, contains lysine, methionine, betain, cholin, proteolytic enzyme, nuclease, urease (Chatterjee and Pakrashi, 2001). The phytochemical investigation of an ethanolic leaf extract of $B$. arundinacea Retz. furnished 6 constituents, two of which represented new natural entities. Remaining four compounds which are previously reported from the other plant sources have been isolated for the first time from the leaves of $B$. arundinacea Retz. Spectroscopic structure elucidation of the new natural products is described. The new compounds are characterized as 17, 20, 20-tri demethyl-20 $\alpha$-isopranyl oleanane and eicosan-1, 20-dioic acid (Kiruba, 2007). The bamboo leaves, obtained from the common tall bamboos (species of Phyllostachys, rather than the small Lophatherum) have recently been utilized as a source of flavonoids (e.g., vitexin and orientin), used as antioxidants. The flavonoids may reduce inflammation, promote circulation, and inhibit allergy reactions. A juice made from the leaves has been made into a bamboo flavored beer (Shastry, 2003). B. arundinacea extract contains Silicates $(60 \%-70 \%)$ which are responsible for its action in curative disease like diarrhoea, dyspepsia, flatulence and worm problems, inflammations, ulcers and wounds (Muniappan and Sundararaj, 2003). Nayak S \& Rout GR analyzed the isolation and characterization of microsatellites in $B$. arundinacea and cross species amplification in other bamboos (Nayak and Rout, 2005). Six microsatellites, three polymorphic and three monomorphic, were characterized in a bamboo species, $B$. aruninacea belonging to the family Poaceae (Tiwari et al., 1982).

\section{Pharmacology \\ Anti-inflammatory and antiulcer activity}

The antiinflammatory effect of the methanol extract of the leaves of $B$. arundinacea against carrageenin-induced as well as immunologically induced paw oedema and also its antiulcer activity in albino rats have been studied and found to be significant when compared to the standard drugs. The combination of methanol extract and phenylbutazone (NonSteroidal Anti-inflammatory Agent, NSAIA) has been studied and found to be the most potent anti-inflammatory activity experimentally with least toxic (no ulcerogenic) activity. Thus, the combination of herbal product (methanol extract of $B$. arundinacea) with modern medicine (NSAIAs) will produce the best anti-inflammatory drug and will be useful for longterm treatment of chronic inflammatory conditions like rheumatoid arthritis with peptic ulcer, which are common (Muniappan and Sundararaj, 2003).

Anthelmintic activity

Ethanolic extract of the root part of $B$. arundinacea was investigated for their anthelmintic activity against Pheritima posthuma. The study involves the determination of paralysis time and death time of the worms in the different doses of the extracts $(10,20$ and $50 \mathrm{mg} / \mathrm{ml})$. The extract exhibited significant anthelmintic activity in a dose dependent manner compared to the control. Activity was comparable with the reference standard Pipeazine citrate $(15 \mathrm{mg} / \mathrm{ml})$ and Albendazole (10 mg/ml) (Kumar, 2012).

\section{Antidiabetic activity}

Aqueous ethanolic solvent extracts of B. arundinacea seed were tested for anti-diabetic activity using alloxan indused diabetic rats and compared with standard. The result expressed that aqueous ethanolic extracts had shown significant protection and maximum reduction in blood glucose was observed in alloxan induced diabetic rats. The results of this comprehensive study reveal that $B$. arundinacea seed shown statistically significant Anti-diabetic activity in comparison to the standard glibenclamide (Macharla, 2011).

\section{Antibacterial activity}

Water-phase extract of bamboo shavings (WEBS), by supercritical carbon dioxide extraction, was evaluated for its antimicrobial action against the range of food borne and food spoilage pathogens using agar disc diffusion assay in nutrient agar and Czapek Dox Agar media. The WEBS exhibited antimicrobial activity against Staphylococcus aureus, Bacillus subtilis, Escherichia coli, Aspergillus niger, Penicilliun citrinum and Saccharomyces cerevisiae with a concentrationdependent relationship (Zhang, 2010).

\section{Protective effects}

Two biological activities of bamboo-derived pyrolyzates were investigated; the protective effects against $\mathrm{N}$-methyl-daspartate (NMDA)-induced cell death in primary cultured cortical neuron and the anti-plasmin effects determined by using fibrin and fibrinogen degradation products (FDPs) assay. Treatment of neuronal cells with pyrolyzates of Phyllostachys pubescens, Phyllostachys nigra and Phyllostachys bambusoides resulted in restored cell viability when compared to untreated cells in an NMDA-induced neuronal cell death assay. In addition, cortical neurons treated with Phyllostachys pubescens and Phyllostachys nigra showed a reduction of apoptosis following 
exposure to NMDA, as determined by Hoechst 33342 staining. In addition, Phyllostachys nigra pyrolyzates also exhibited antiplasmin action in a FDP assay. It is of interest to note that pyrolyzates exhibited activities of NMDA-receptor antagonist and antifebrin (ogen), since a combination of NMDA receptor antagonists, glucocorticosteroids, GABAergic drugs and heparin are useful for treatment in delayed postischemic injury. Results indicate that the pyrolyzates derived from bamboo may have antiapoptotic effects, and can be useful as a supplement for ischemic injury treatment (Rathod, 2012).

\section{Antifertility activity}

An ethanolic extract of $B$. arundinacea tender shoots (BASE) caused a reduction in fertility of male rats. After administration of $300 \mathrm{mg} / \mathrm{kg}$ per day of BASE for 7 days, the fertility index decreased to $15 \%$ for control rats and to $23 \%$ after a 7 -day recovery period, respectively. The number of cohabited females being successfully inseminated was reduced especially after 4 days of treatment. Complete recovery of mating behavior was evident 8 days after BASE withdrawal. The number of spermatozoa in the caput and cauda epididymis were decreased concomitant with a decrease in the motility of spermatozoa collected from the cauda epididymis. The weights of testes, epididymides, vas deferens and prostate were also significantly decreased. The serum profile of protein and oxaloacetic/pyruvic transaminase activity show the extract to be relatively nontoxic (Brandis, 1972).

\section{Insecticidal activity}

Asian Centers of Diversity, bamboos are reported to tolerate insects, laterites, low $\mathrm{pH}$, slope, and weeds $(2 n=72,70)$. Eight grams of raw shoots or slightly more improperly cooked shoots can cause death. Young shoots contain 0.03\% HCN (C.S.I.R., 1948-1976). Hairs on various bamboos, and fungi which live thereon, may cause dermatitis. Benzoic acid and traces of cyanogenic glucoside present in shoots have lethal effect on mosquito larvae (has antiseptic and larval properties) (Anonymous 1996).

\section{Antiarthritic activity}

Anti-arthritic activity of $B$. arundinacea in treating rheumatoid Arthritis (RA) using CFA-induced arthritis animal model was investigated. The effect of $B$. arundinacea methanolic extract on the arthritis was studied by analyzing various markers of Bone erosion like histological, radiological analysis of the joints. For evaluation of anti-arthritic activity other parameters analyzed are Paw volume, Arthritic index, Rheumatoid Factor, Erythrocyte Sedimentation Rate (ESR) and Spleen histopathology. The powdered leaves are used for hot extraction by using methanol as solvent. The anti-arthritic activity of the dry extracts was performed using female rats of about 200 to 250 gms. The methanolic extract of $B$. arundinacea significantly (dose dependent) decreased the bone erosion, spleen enlargement $\&$ rheumatoid factor etc. at a dose $(100 \mathrm{mg} / \mathrm{kg}, 200 \mathrm{mg} / \mathrm{kg}, 300 \mathrm{mg} / \mathrm{kg}$ ) compared to the control group but less compared to Standard drug (Dexamethasone 5 $\mathrm{mg} / \mathrm{kg}$ i.p) (Rathod et al, 2012).

\section{In cosmetics \\ Antioxidant activity of flavanoids}

The antioxidant activity of flavanoids results from the combination of their iron chelating activity and their ability to scavange ageing- induced free radical. Flavanoid can inhibit oxidases such as lipooxygenase, cyclooxyegenase and xanthine oxidase, thus preventing the invivo formation of reactive oxygen species and organic hydroperoxidase. Additionally, it has been found that flavanoid inhibit enzymes indirectly involved in oxidative processes. Flavanoids shows antiaging, photoprotection and hair color protection (Macwan et al, 2010).

\section{Vessles protection and venotonic activities}

Flavanoids are vein active and vessel-protective agents because they reduce the permeability and increase the resistance of blood capillaries. Flavanoids are used in the treatment of blood vessel disorders such as varices, chronic venous insufficiency, low capillary resistance etc. Oral administration of flavanoid s has been observed to effectively improve the capillary resistance in animal models (Mukesh et al., 2005).

Acute and subchronic toxicity studies on anti-oxidant of bamboo leaves.

The anti-oxidant of bamboo leaves (AOB) has recently been certificated as a novel kind of natural anti-oxidant by the Ministry of Health of the Peoples Republic of China, and has been used in various food systems. Here, AOB was subjected to a series of acute and subchronic toxicological tests to evaluate its safety. The results showed that the maximum tolerated dose (MTD) of AOB was $>10 \mathrm{~g} / \mathrm{kg}$ body weight in both rats and in mice, which can be regarded as virtually non-toxic. No mutagenicity evidence was detected in any of the three mutagenic tests. Administration at levels of 1.43, 2.87 and 4.30 $\mathrm{g} / \mathrm{kg}$ per day to the rats for 90 days did not induce significant hematological, clinic, chemical and histopathological changes, and suggested a no-observed adverse- effect level (NOAEL) of $4.30 \mathrm{~g} / \mathrm{kg}$ per day. These results indicate that AOB can be generally regarded as safe for use as a food additive (Baiyi et al, 2005; Nazreen et al 2011; Christine and Martyn, 2000).

Effects of bamboo buds: structural and functional changes in the epididymis of rats.

An ethanolic extract of the tender shoots of $B$. arundinaceae was administered at $300 \mathrm{mg} / \mathrm{kg}$ per rat per day for 7 days to adult male rats to assess epididymal structural and functional activity. Sperm motility decreased markedly in the cauda epididymal fluid and sperm count decreased significantly in both caput and caudal segments of the epididymis. Histologically, a reduction in epithelial and stereocilia height (in both segments) and lumen diameter (in cauda) was noted. An increase in intertubular stroma was also evident. Epididymal weights, activities of acid phosphatase and total LDH were reduced in both epididymal segments. Protein concentration was appreciably increased only in the caudal segment. Extract therapy impaired the structural and functional integrity of the epididymis (Joshi et al, 2009; Sharma, 1996).

\section{Misllaneous}

$>$ Bamboo is the main food of the Giant Panda; it makes up 99\% of the Panda's diet. Soft bamboo shoots, stems, and leaves are the major food source of the Giant Panda of China.

$>$ Bamboo is used in Chinese medicine for treating infections and healing. It is a low-calorie source of potassium. It is known for its sweet taste and as a good source of nutrients and protein.

$>$ When bamboo is heated at very high temperature in an airless vessel, it becomes charcoal, which is used like other charcoal products, as a fuel component, a deodorizer, or an absorbent. The vapor that comes off the heated bamboo can be condensed to produce a liquid known as bamboo vinegar. Bamboo vinegar has been produced in Japan (where it is called chikusaku-eki) for many years and is used medicinally to treat eczema, atopic dermatitis, and other skin diseases; it is most commonly applied by adding to bath water. Bamboo vinegar is recognized as an anti-inflammatory and anti-fungal.

$>$ Pickled bamboo, used as a condiment, may also be made from the pith of the young shoots.

$>$ In addition, bamboo is frequently used for cooking utensils within many cultures. In modern times, some see 
bamboo tools as an eco-friendly alternative to other manufactured utensils

$>$ In Ayurveda, the Indian system of traditional medicine, the silicious concretion found in the culms of the bamboo stem is called banslochan. It is known as tabashir or tawashir in Unani-Tibb the Indo-Persian system of medicine. In English it is called "bamboo manna". This concretion is said to be a tonic for the respiratory diseases.

$>$ In addition, the fiber of bamboo has been used to make paper in China since early times. A high quality hand-made paper is still produced in small quantities. Coarse bamboo paper is still used to make spirit money in many Chinese commun Bamboo's natural hollow form makes it an obvious choice for many instruments, particularly wind and percussion. There are numerous types of bamboo flute made all over the world, such as the dizi, xiao, shakuhachi, palendag, jinghu, angklung. ities

> Bamboo was in widespread use in early China as a medium for written documents. The earliest surviving examples of such documents, written in ink on string-bound bundles of bamboo strips (or "slips"), date from the 5th c. BC during the Warring States period.

\section{Important formulations}

- $\quad$ Sitopaladi churna

- Talisadi churna

Genuine Bamboo-manna is difficult to procure. Curcuma angustifolia is in use as a substitute. Its original name, Tabashiri, was equated in due course the Tabasheer of Unani medicines (Gupta, 2008).

Possible Combinations: B. arundinacea + Piper longum + Cinnamomum camphora (curing lung disease)

Recommended dose: The recommended dose is between $0.5 \%$ and $5.0 \%$.

\section{CONCLUSION}

Herbs are an integral part of nature. Herbal medicine is based upon the premise that plants contain natural substance that can promote health and alleviate diseases. To treat various ailments most of local population depends on native medicinal plants. This paper reports ethnomedical uses phytochemicals present and biological activities of $B$. arundinacea that is commonly used in traditional system of medicines. The reported biological activities are the outcome of the traditional claims. The present literature supports the potential of Bambusa arundinacea as a medicinal tree mankind and justifies the inclusion of these drugs in traditional preparation.

\section{ACKNOWLEDGMENTS}

The authors thanks to Director B R Nahata College of Pharmacy, Mandsaur College of Pharmacy and Management for their kind support.

\section{CONFLICT OF INTEREST}

The authors declare that there are no conflicts of interest.

\section{REFERENCES}

Anonymous, The Wealth of India. (New Delhi, India: National
Institute of Science Communications and Information Resources.CSIR), p.114, 1985.

Atal CK, Kapur BM. Cultivation and Utilization of Medicinal plant. (Jammu-Tavi, India: Regional Research Laboratory, CSIR), pp.514-519, 1982.

Baiyi L, Xiaoqin W, Xiaowei T, Zhang Y, Zhang Y. Acute and subchronic toxicity studies on anti-oxidant of bamboo leaves. Food and ChemToxi. 2005;12:783-792.

Bhaduri B, Ghose CR, Bose AN, Moza BK, Basu UP. Antifertility activity of some medicinal plants. Ind J Exp Bio.1968;6:252-253.

Chatterjee A, Pakrashi SC. The Treatise on Indian Medicinal plants. (New Delhi, India: National Institute of Science communication), pp. 50-51, 2001.

Chatterjee TK. Herbal options. (Calcutta, India: M/s Estern Trader), pp. 70-128, 1996.

Chen TH, Huang YC, Yang CS, Yang CC, Wang AY, Sung HY. Insights into the catalytic properties of bamboo vacuolar invertase through mutational analysis of active site residues. Phytochemistry. 2009;70:25-31.

Chopra RN, Chopra IC, Handa KL, Kapur LD. Chopra's Indigenous Drug of India. (Calcutta, India: U.N. Dhar and Sons Pvt. Ltd), 1958.

Christine FS, Martyn TS. Potential health impacts of excessive flavonoid intake. Free Radic Biol Med. 2000;29:375-383.

Gupta DP. The Herbs Habitat Morphology \& Pharmacognosy of most important popular plants. $1^{\text {st }}$ ed. (Indore, India: Print well offset), pp.73-74, 2008.

Hong EJ, Jung EM, Lee GS, Kim JY, Na KJ, Park MJ, Kang HY, Choi KC, Seong YH, Choi IG, Jeung EB. Protective effects of the pyrolyzates derived from bamboo against neuronal damage and hematoaggregation. J Ethnopharmacol. 2010;128:594-599.

Jarald E, Joshi SB, Jain DC. A brief review on few Indian medicinal plants. Inter J of green pharm. 2007;1:2-13.

Joshi RK, Patil PA, Mujawar MHK, Kumar D, Kholkute SD. Hypoglycemic activity of B. arundinacea leaf aqueous extract in euglycemic and hyperglycemic wistar rats. Pharmacologyon. 2009;3:789-795.

Kirtikar KR, Basu BD. Indian Medicinal Plants. 3rd ed. (Dehradun, India: International Book Distributor), pp. $2327-$ 2328, 1999.

Kiruba S, Jeeve S, Manohardas S, Kannan D. Bamboo seed as a mean to sustenance of the indigenous community. Indian $\mathbf{J}$ Tradit Know. 2007;6:199-203.

Kumar D, Kumar A, PrakashO. Potential antifertility agents from plants: A comprehensive review. J Ethnopharmacol. 2012;140:1-32.

Kumar HKS, Raju MBV, Dinda SC, Sahu S. Evaluation of anthelmintic activity of B.arundinacea. Asian J Pharm Tech.

2013 / Volume 3 / Issue 3 / e20 
2012;2:62-63.

Macharla SP. Antidiabetic activity of Bambusaarundinacea seed extract on alloxan induced diabetic rats. Int J Pharmaceut Res Dev. 2011;3:83-86.

Macwan C, Patel HV,Kalia K. A comparative evaluation of in vitro antioxidant properties of Bamboo leaves extracts. J Cell Tissue Res. 2010;10:2413-2418.

Mukesh N, Ojha SK, Arya DS. Protective role of flavanoids in cardiovascular diease. Natural product Radiance. Nat prod radiance. 2005;4:166-177.

Muniappan M, Sundararaj T. Anti-inflammatory and antiulcer activities of Bambusaarundinacea. $\mathrm{J}$ Ethanopharmacol. 2003;88:161-167.

Nandkarni KM. Indian MateriaMedica.3rd ed. (Bombay, India: Bombay Popular Prakashan), pp.173-175, 2000.

Nayak S, Rout GR. Isolation and characterization of micro satellites in Bambusa arundinacea and cross species amplification in other bamboos. African $\mathrm{J}$ Biotechnol. 2005;4:151-156.

Nazreen S, Alam MS, Hamid H, Kaur G, Alam MM , Haider S, Shafi S. Phytochemical investigation of BambusaarundinaceaRetz. Int J Nat Prod Sci. 2011;3:1-7.

Rastogi RP, Mehrotra BN. Compendium of Indian Medicinal Plants, (Vol.I), Publication and information directorate. (New Delhi, India: Centre for Scientific and Industrial Research), pp 188-189, 1993.

Rathod JD, Pathak NL, Patel RG, Jivani NP, Patel LD, Chauhan V. Ameliorative effect of Bambusa arundinacea against adjuvant arthritis-with special reference to bone erosion and tropical splenomegaly. J Drug Deliv Ther. 2012;2:141-145.

Rousset P, Aguiar C, Labbé N, Commandré JM. Enhancing the combustible properties of bamboo by torrefaction. Bioresour Technol. 2011;102:8225-8231.

Satya S, Bal LM, Singhal P, Naik SN. Bamboo shoot processing: food quality and safety aspect (a review). Trends Food Sci Tech. 2010;21:181-189.

Sharma PV. Classical uses of medicinal plants, Chaukhambha. (Varanasi, India, Visvabharati), 1996.

Tiwari KC, Majumder R, Bhattacharjee, S. Folklore information from Assam for family planning and birth control. Int J Crude Drug Res. 1982;20:133-137.

Vanithakumari G, Manonayagi S, Padma S, Malini T. Antifertility effect of Bambusa arundinacea shoot extracts in male rats. J Ethnopharmacol. 1989;25:173-80.

Watt G. A Dictionary of the Economic Products of India. Reprinted ed. (New Delhi, India: Government Printing), 1972.

Wen JL, Xiao LP, Sun YC, Sun SN, Xu F, Sun RC, Zhang XL. Comparative study of alkali-soluble hemicelluloses isolated from bamboo (Bambusarigida). Carbohydr Res. 2011;346:11120.

Zhang J, Gong J, Ding Y,Lu B, Wu X, Zhang Y. Antibacterial activity of water-phase extracts from bamboo shavings against food spoilage microorganisms. African $\mathrm{J}$ Biotechnol. 2010;9:7710-7717. 